\title{
PENGUJIAN KUALITAS DAN KOMPOSISI KIMIA MINYAK NILAM (Pogostemon cablin benth) SETELAH PENYIMPANAN
}

\author{
Syarifatuz Zaimah \\ Program Studi Kimia \\ Fakultas Matematika dan Ilmu Pengetahuan Alam \\ Universitas Islam Indonesia
}

\begin{abstract}
ABSTRAK
Telah dilakukan penelitian untuk menguji kualitas dan komposisi kimia minyak nilam (Pogostemon cablin benth) yang telah disimpan selama tiga bulan. Minyak nilam yang dimaksud diperoleh sebelumnya dari proses distilasi uap dengan menggunakan variasi $\mathrm{pH}$ air penyuling yaitu $\mathrm{pH}$ 7, 9, 10 dan 12. Metode yang dilakukan adalah dengan menganalisis sifat fisika sampel yaitu berat jenis, indeks bias dan sifat kimia yaitu bilangan asam, bilangan ester, Fe serta komponen kimianya dengan GC-MS. Hasil penelitian menunjukkan bahwa sifat fisika minyak nilam setelah penyimpanan tiga bulan tidak mengalami perubahan untuk setiap variasi $\mathrm{pH}$ air penyuling. Sementara hasil uji sifat kimia terhadap angka asam untuk $\mathrm{pH}$ 7, 9, 10 dan 12 adalah 0,00460; 0,00488; 0,00354 dan 0,01160; angka ester: 0,01027; 0,00736; 0,00672 dan 0,01376; dan kandungan Fe: 4,6389 mg/L; 4,0806 mg/L; 3,1374 mg/L dan 6,4271 mg/L. Analisis komposisi kimia menunjukkan adanya senyawa-senyawa yang sama pada setiap variasi $\mathrm{pH}$ air penyuling sebelum dan setelah penyimpanan minyak nilam yaitu: transkaryofilena, $\alpha$-patchoulena, $\alpha$-guaiena, $\delta$-guaiena, $\beta$-elemena, seycellena, patchoulena dan $\beta$-karyofilena. Namun secara kuantitatif mengalami perubahan. Sementara itu senyawa utama minyak nilam yaitu patchouli alcohol tidak dijumpai.

Kata kunci: minyak nilam, penyimpanan tiga bulan, $p H, G C-M S$
\end{abstract}

\begin{abstract}
Research has been conducted to test the quality and chemical compositions of patchouli (Pogostemon cablin Benth) that had been stored for three months. Patchouli oil is obtained from steam distillation process by using a variations of $\mathrm{pH}$ of the distilled water at $\mathrm{pH} \mathrm{7,} \mathrm{9,} 10$ and 12. The method has been done by analyzing the physical properties of the sample is density, refractive index and chemical properties is acid number, ester number, Fe and chemical components by GC-MS. The results showed that the physical properties of patchouli oil after three months of storage did not change on each variations of $\mathrm{pH}$ of the distilled water. The test results of the chemical properties of the acid number to $\mathrm{pH} 7,9,10$ and 12 are $0.00460 ; 0.00488 ; 0.00354$ and 0.01160 ; ester number: 0.01027; 0.00736; 0,00672 and 0,01376 and Fe content: 4,6389 mg/L; 4,0806 $\mathrm{mg} / \mathrm{L} ; 3,1374 \mathrm{mg} / \mathrm{L}$ and 6,4271 mg/L. Analysis of chemical components showed the same compounds at each variation of $\mathrm{pH}$ of the distilled water before and after storage of patchouli oil are: trans-caryophyllene, $\alpha$-patchoulene, $\alpha$-guaiene, $\delta$-guaiene, $\beta$-elemene, seycellene, patchoulene and $\beta$-caryophyllene. However, quantitative changes. The main compound of patchouli oil is patchouli alcohol was not found.
\end{abstract}

Keywords : patchouli oil, three months of storage, $\mathrm{pH}, \mathrm{GC}-\mathrm{MS}$.

\section{PENDAHULUAN}

Minyak nilam adalah minyak atsiri yang diperoleh dari daun, batang dan cabang tanaman nilam dengan cara penyulingan.
Kandungan minyak nilam tertinggi terdapat pada bagian daun yaitu sekitar 4-5\% (Hayani, 2005). Komponen utama yang menentukan mutu minyak nilam adalah patchouli 
alkohol $\left(\mathrm{C}_{15} \mathrm{H}_{26} \mathrm{O}\right)$ yang merupakan senyawa kelompok seskuiterpen alkohol tersier trisiklik yang mempunyai gugus hidroksil yaitu gugua $-\mathrm{OH}$ dan 4 buah gugus metil (Walker, 1969). Kadar patchouli alkohol yang tinggi dalam minyak nilam berarti semakin baik kualitas minyak tersebut.

Minyak nilam digunakan dalam industri kosmetik, parfum, pemberi aroma pada pasta gigi, industri sabun, kebutuhan industri makanan, kebutuhan farmasi, dupa dan kebutuhan industri lainnya (Mangun, 2008). Penggunaan minyak nilam dalam industri-industri ini karena sifat daya fiksasinya yang cukup tinggi terhadap bahan pewangi lain agar aroma bertahan lama, sehingga dapat mengikat bau wangi dan mencegah penguapan zat pewangi.

Mutu minyak nilam yang dihasilkan dari penyulingan tanaman nilam harus memenuhi standar mutu perdagangan yang sudah ditetapkan oleh Standar Nasional Indonesia (SNI-06-2385-2006). Selain itu, penyimpanan minyak juga merupakan hal penting yang harus diperhatikan.

Untuk mengetahui komponen kimia yang terkandung di dalam minyak nilan digunakan analisis dengan GC-MS. Sampai saat ini telah banyak dilakukan penelitian terkait tentang penyulingan minyak atsiri.

Telah dilakukan penelitian oleh Setiyowati (2013), analisis Modifikasi pH air penyuling pada proses ekstraksi nilam secara destilasi uap menggunakan variasi $\mathrm{pH}$ air penyuling dengan penambahan $\mathrm{NaOH} 1 \mathrm{M}$ hingga tercapai pH 9, 10 dan 12. Dari hasil analisis menggunakan GC-MS diperoh hasil bahwa komponen penyusun utama pada minyak atsiri nilam menggunakan air $\mathrm{pH} 7$ yaitu alpha-guaiene (14,12\%), seychellene (8,16\%), alpha-patchoulene (5,94\%), delta-guaiene $\quad(15,42 \%)$ dan patchouli alkohol (34,5\%). Sedangkan pada minyak atsiri nilam menggunakan air $\mathrm{pH} 9$ yaitu alphaguaiene (14,56\%), seychellene (7,97\%), alpha-patchoulene (5,89\%), delta-guaiene $\quad(15,78 \%)$ dan patchouli alkohol (35,62\%). Pada $\mathrm{pH}$ 10 dan 12 tidak terdeteksi adanya patchouli alkohol.

Mutu minyak nilam terutama kandungan patchouli alkohol dalam minyak nilam sangat mempengaruhi kualitas serta komoditi ekspor minyak, maka perlu dilakukan penelitian terhadap komponen kimia minyak nilam tersebut. Oleh sebab itu, peneliti mengusulkan untuk melakukan penelitian tentang komposisi kimia minyak nilam yang telah disimpan selama tiga bulan dengan menggunakan GC-MS. Diharapkan dalam penelitian ini minyak nilam yang telah disimpan selama tiga bulan tidak mempengaruhi komposisi kimia yang ada di dalam minyak nilam terutama tidak menurunkan rendemen patchouli alkoholnya. Selain itu, perlu juga dilakukan analisis berat jenis, indeks bias, bilangan asam, dan bilangan ester sesuai Standar Nasional Indonesia serta kandungan logam besi $(\mathrm{Fe})$ dengan analisis Spektrofotometri Absorpsi Atom untuk mengetahui kualitas minyak nilam yang sesuai dengan SNI dan standar perdagangan dunia. 


\section{METODE PENELITIAN}

\section{Bahan}

Bahan yang digunakan untuk penelitian yaitu sampel minyak nilam hasil penyulingan daun nilam jenis sidikalang yang berasal dari daerah Banjarnegara-Jawa Tengah, asam oksalat, $\mathrm{NaOH} \quad 0,1 \mathrm{~N}$, akuades, indikator Fenolftalein, Etanol, Natrium karbonat, $\mathrm{HCl} 0,1 \mathrm{M}$, indikator Metil orange, $\mathrm{NaOH} 10 \mathrm{~N}$ dan $\mathrm{HNO}_{3}$ pekat.

\section{Alat}

Alat-alat yang digunakan dalam penelitian ini adalah neraca analitik, labu ukur, pipet tetes, buret, erlenmeyer, gelas beker, piknometer, termometer, spatula, magnetic stirer, refraktometer, cawan porselen, furnace, kertas saring whatman, oil bath, AAS dan GC-MS model Shimadzu QP 2010S.

\section{Penentuan Sifat Fisika-Kimia Minyak Nilam}

\section{Pengukuran Berat Jenis}

Piknometer kosong yang sudah bebas dari air ditimbang dengan neraca analitik dan dicatat beratnya sebagai berat piknometer kosong. Piknometer kemudian diisi akuades secara perlahan-lahan hingga penuh sampai tidak terjadi gelembung udara dan direndam pada suhu $25^{\circ} \mathrm{C}$ selama 30 menit. Selanjutnya, piknometer diangkat dan dibersihkan sampai bersih lalu ditimbang dengan neraca analitik (berat piknometer + air). Kemudian dengan langkah sama piknometer diisi dengan minyak nilam dan ditimbang lalu dicatat sebagai berat piknometer + minyak.

$$
\text { Berat jenis }=\frac{(\mathrm{A})-(\mathrm{B})}{(\mathrm{C})-(\mathrm{B})}
$$

Keterangan:

A : piknometer + minyak

$\mathrm{B}$ : berat piknometer kosong

$\mathrm{C}$ : berat piknometer + air

\section{Pengukuran Indeks Bias}

Indeks bias, diukur dengan alat yang disebut refraktometer. Langkah pertama yang dilakukan yaitu membersihkan prisma pada refraktometer dengan larutan alkohol dan dikeringkan menggunakan tisu. Permukaan prisma lalu ditetesi dengan minyak nilam dan ditutup. Untuk mengetahui nilai indeks bias dilakukan dengan cara memutar skrup atau slide sampai didapatkan garis yang jelas antara bidang yang gelap bidang yang terang. Apabila garis berhimpit dengan titik potong dari kedua batas garis yang bersilangan, maka dibiarkan selama beberpa menit lalu indeks bias dapat dibaca.

\section{Penentuan Bilangan Asam}

Sampel minyak nilam ditimbang sebanyak 0,4 gram kemudian ditambahkan $10 \mathrm{~mL}$ pelarut etanol. Larutan diaduk menggunakan magnetic stirrer sampai tercampur dengan sempurna. Kemudian ditambahkan 5 tetes indikator fenolftalein lalu dititrasi dengan larutan $\mathrm{NaOH} 0,01 \mathrm{~N}$ yang sudah distandarisasi sebelumnya. Langkah selanjutnya, diamati perubahan warna larutan dari warna kuning menjadi merah muda, dan dicatat volume hasil akhir titrasi. Langkah di atas dilakukan perlakuan yang sama pada masing-masing sampel minyak nilam yang menggunakan air penyuling $\mathrm{pH}$ 7, 9, 10 dan 12.

$$
\mathrm{V}_{\text {titrasi }} \mathrm{N}_{\mathrm{NaOH}}
$$

Bilangan Asam = 


\section{Berat Sampel \\ 4. Penentuan Bilangan Ester}

Sampel minyak nilam ditimbang sebanyak 0,4 gram. Setelah itu, ditambahkan $10 \mathrm{~mL} \mathrm{NaOH} 0,05 \mathrm{~N}$ dari larutan $\mathrm{NaOH} 10 \mathrm{~N}$ dengan menggunakan rumus pengenceran. Selanjutnya, larutan direfluks sampai mendidih, lalu didiamkan supaya dingin. Kemudian ditambahkan 5 tetes indikator fenolftalein lalu dilakukan titrasi dengan larutan $\mathrm{HCl}$ 0,05 $\mathrm{N}$ yang sudah distandarisasi

\section{Analisis Kandungan Besi (Fe)}

Analisis kandungan besi pada sampel minyak nilam menggunakan metode destruksi kering. Langkah yang dilakukan dalam analisis yaitu sampel minyak nilam ditimbang sebanyak 0,5 gram dalam cawan porselen kemudian dipanaskan dalam furnace dengan suhu $800^{\circ} \mathrm{C}$ selama 2 jam. Setelah 2 jam furnace dimatikan dan sampel disimpan dalam furnace selama satu hari satu malam. Selanjutnya, sampel yang sudah didinginkan selama satu hari satu malam ditambahkan sebanyak $5 \mathrm{~mL}$ $\mathrm{HNO}_{3}$ pekat, lalu dipanaskan sampai larut sempurna dan didinginkan. Kemudian, ditambahkan dengan 10 $\mathrm{mL}$ akuades lalu disaring dengan kertas saring whatman dan langkah terakhir sampel yang sudah didestruksi dianalisis dengan SSA (Spektrofotometer Absorpsi atom) di Lab. Terpadu, Lab. Instrumentasi, Fisika dan Kimia dasar Universitas sebelumnya. Titrasi dilakukan sampai terjadi perubahan warna larutan dari merah muda menjadi putih kekuning-kuningan dan dicatat volume hasil akhir titrasi. Langkah di atas dilakukan perlakuan yang sama pada masing-masing sampel minyak nilam yang menggunakan air penyuling $\mathrm{pH}$ 7, 9, 10 dan 12 .

$$
\mathrm{BM}_{\mathrm{NaOH}}\left(\mathrm{V}_{\text {blanko }}-\mathrm{V}_{\text {sampel }}\right) \times \mathrm{N}_{\mathrm{HCl}} \mathrm{x}
$$

Bil. Ester

Berat sampel (gram)

Islam Indonesia. Langkah di atas dilakukan perlakuan yang sama pada masing-masing sampel minyak nilam yang menggunakan air penyuling $\mathrm{pH}$ 7, 9, 10 dan 12.

\section{Penentuan Komposisi Kimia Minyak Nilam}

Analisis komposisi kimia di dalam minyak nilam diidentifikasi menggunakan seperangkat alat Gas Chromatography-Mass Spectroscopy (GC-MS) model Shimadzu QP 2010S, di Lab. Kimia Organik FMIPA UGM. Kondisi alat ketika analisis yaitu kolom jenis DB-1 (diameter dalam $30 \mathrm{~m}$ x 0,25 mm). Temperatur kolom diatur pada suhu $70^{\circ} \mathrm{C}$ selama 5 menit dan meningkat hingga suhu 280 Temperatur injektor dan sumber ion (EI pada 70 eV) 250 dan 306. Gas pembawa yang digunakan adalah Helium (He) dengan kecepatan alir $3 \mathrm{~mL} /$ menit. Range scan SM adalah m/z 28-600. 


\section{HASIL DAN PEMBAHASAN}

\section{Penentuan Sifat Fisika-Kimia Minyak Nilam}

Hasil analisis sifat fisika kimia pada minyak nilam dengan air penyuling $\mathrm{pH}$ 7, 9, 10 dan 12 setelah penyimpanan disajikan pada Tabel 1.

Tabel 1. Hasil Analisis Sifat Fisika-Kimia Minyak Nilam Segar dan Minyak Nilam Setelah Penyimpanan Sesuai SNI-06-2385-2006

\begin{tabular}{|c|c|c|c|c|c|}
\hline No & Jenis Uji & Ket. & $\begin{array}{c}\text { Persyaratan } \\
\text { (SNI-06-2385- } \\
\text { 2006) }\end{array}$ & Minyak Nilam (A) & Minyak Nilam (B) \\
\hline \multirow{4}{*}{1} & \multirow{4}{*}{ Warna } & $\mathrm{pH} 7$ & \multirow{4}{*}{$\begin{array}{l}\text { Kuning muda- } \\
\text { coklat kemerahan }\end{array}$} & $\begin{array}{c}\text { Kuning kecoklatan } \\
\text { (jernih) }\end{array}$ & $\begin{array}{c}\text { Kuning kecoklatan } \\
\text { (jernih) }\end{array}$ \\
\hline & & pH 9 & & $\begin{array}{c}\begin{array}{c}\text { Kuning kecoklatan } \\
\text { (keruh) }\end{array} \\
\end{array}$ & $\begin{array}{c}\text { Kuning kecoklatan } \\
\text { (keruh) }\end{array}$ \\
\hline & & $\mathrm{pH} 10$ & & $\begin{array}{c}\text { Kuning kecoklatan } \\
\text { (keruh) }\end{array}$ & $\begin{array}{c}\text { Kuning kecoklatan } \\
\text { (keruh) }\end{array}$ \\
\hline & & $\mathrm{pH} 12$ & & Merah kecoklatan & Merah kecoklatan \\
\hline \multirow{4}{*}{2} & \multirow{4}{*}{$\begin{array}{l}\text { Berat Jenis } \\
25^{\circ} \mathrm{C}\end{array}$} & $\mathrm{pH} 7$ & \multirow{4}{*}{ 0,950-0,975 } & 0,9620 & 0,9705 \\
\hline & & pH 9 & & 0,9630 & 0,9668 \\
\hline & & $\mathrm{pH} 10$ & & 0,9670 & 0,9594 \\
\hline & & $\mathrm{pH} 12$ & & 0,9780 & 0,9608 \\
\hline \multirow{4}{*}{3} & \multirow{4}{*}{$\begin{array}{l}\text { Indeks Bias } \\
\left(\mathrm{nD}^{20}\right)\end{array}$} & $\mathrm{pH} 7$ & \multirow{4}{*}{$1,507-1,515$} & 1,5050 & 1,5055 \\
\hline & & $\mathrm{pH} 9$ & & 1,5040 & 1,5050 \\
\hline & & $\mathrm{pH} 10$ & & 1,5040 & 1,5045 \\
\hline & & pH 12 & & 1,5060 & 1,5065 \\
\hline \multirow{4}{*}{4} & \multirow{4}{*}{ Bilangan asam } & $\mathrm{pH} 7$ & \multirow{4}{*}{ Maks. 8} & - & 0,00460 \\
\hline & & pH 9 & & - & 0,00488 \\
\hline & & $\mathrm{pH} 10$ & & - & 0,00354 \\
\hline & & pH 12 & & - & 0,11600 \\
\hline \multirow{4}{*}{5} & \multirow{4}{*}{ Bilangan ester } & $\mathrm{pH} 7$ & \multirow{4}{*}{ Maks. 20} & - & 0,01027 \\
\hline & & $\mathrm{pH} 9$ & & - & 0,00736 \\
\hline & & $\mathrm{pH} 10$ & & - & 0,00672 \\
\hline & & $\mathrm{pH} 12$ & & - & 0,01376 \\
\hline \multirow{4}{*}{6} & \multirow{4}{*}{$\begin{array}{l}\text { Patchouli } \\
\text { alkohol } \\
\left(\mathrm{C}_{15} \mathrm{H}_{26} \mathrm{O}\right)(\%)\end{array}$} & $\mathrm{pH} 7$ & \multirow{4}{*}{ Min. $30 \%$} & 34,50 & - \\
\hline & & pH 9 & & 35,62 & - \\
\hline & & $\mathrm{pH} 10$ & & - & - \\
\hline & & pH 12 & & - & - \\
\hline \multirow{4}{*}{7} & \multirow{4}{*}{$\begin{array}{l}\text { Kandungan } \\
\text { Besi (Fe) } \\
(\mathrm{mg} / \mathrm{L}) \\
\end{array}$} & $\mathrm{pH} 7$ & \multirow{4}{*}{ Maks. 25 mg/L } & - & 4,6389 \\
\hline & & $\mathrm{pH} 9$ & & - & 4,0806 \\
\hline & & $\mathrm{pH} 10$ & & - & 3,1375 \\
\hline & & pH 12 & & - & 6,4271 \\
\hline
\end{tabular}

Keterangan:

(A) : sampel minyak nilam segar

(B) : sampel minyak nilam setelah penyimpanan

Jika dibandingkan sifat fisikakimia minyak nilam sebelum dan setelah penyimpanan pada Tabel 1 menunjukkan bahwa pada pengukuran berat jenis terjadi perubahan yang tidak signifikan. Secara keseluruhan hasil pengukuran indeks bias minyak nilam di bawah standar, namun setelah disimpan selama tiga bulan ada kenaikan indeks bias. Sedangkan nilai bilangan asam dan bilangan ester relatif sangat kecil, kemungkinan hal tersebut disebabkan karena terjadi kesalahan ketika melakukan analisis terutama ketika titrasi. Sebab yang lain dapat juga karena human error atau mungkin juga variasi $\mathrm{pH}$ air penyuling berpengaruh pada kecilnya bilangan asam dan ester. Uji kualitas 
minyak nilam pada kandungan logam besi (Fe) masih memenuhi standar yang ditentukan oleh SNI sebesar 25 $\mathrm{mg} / \mathrm{L}$.

\section{Penentuan Komposisi Kimia Minyak Nilam}

Dari hasil analisis dengan GCMS didapatkan komponenkomponen senyawa kimia yang terdapat pada sampel minyak nilam dengan menggunakan air penyuling $\mathrm{pH} \mathrm{7,} \mathrm{9,} 10$ dan 12. Kromatogram komponen kimia minyak nilam diperlihatkan pada Gambar 1.
Dengan membaca data hasil kromatogram menunjukkan bahwa senyawa kimia yang terdapat dalam sampel minyak nilam yang teridentifikasi yaitu beta-elemene, trans-caryophyllene, seychellene, alpha-patchoulene, alpha-guaiene, alpha-selinene, beta-caryophyllene, delta-guaiene, patchoulene, dan valeranone. Identifikasi komponenkomponen kimia minyak nilam dilakukan dengan melihat databese dan membandingkan massa spektra masing-masing komponen yang teridentifikasi dengan literatur.
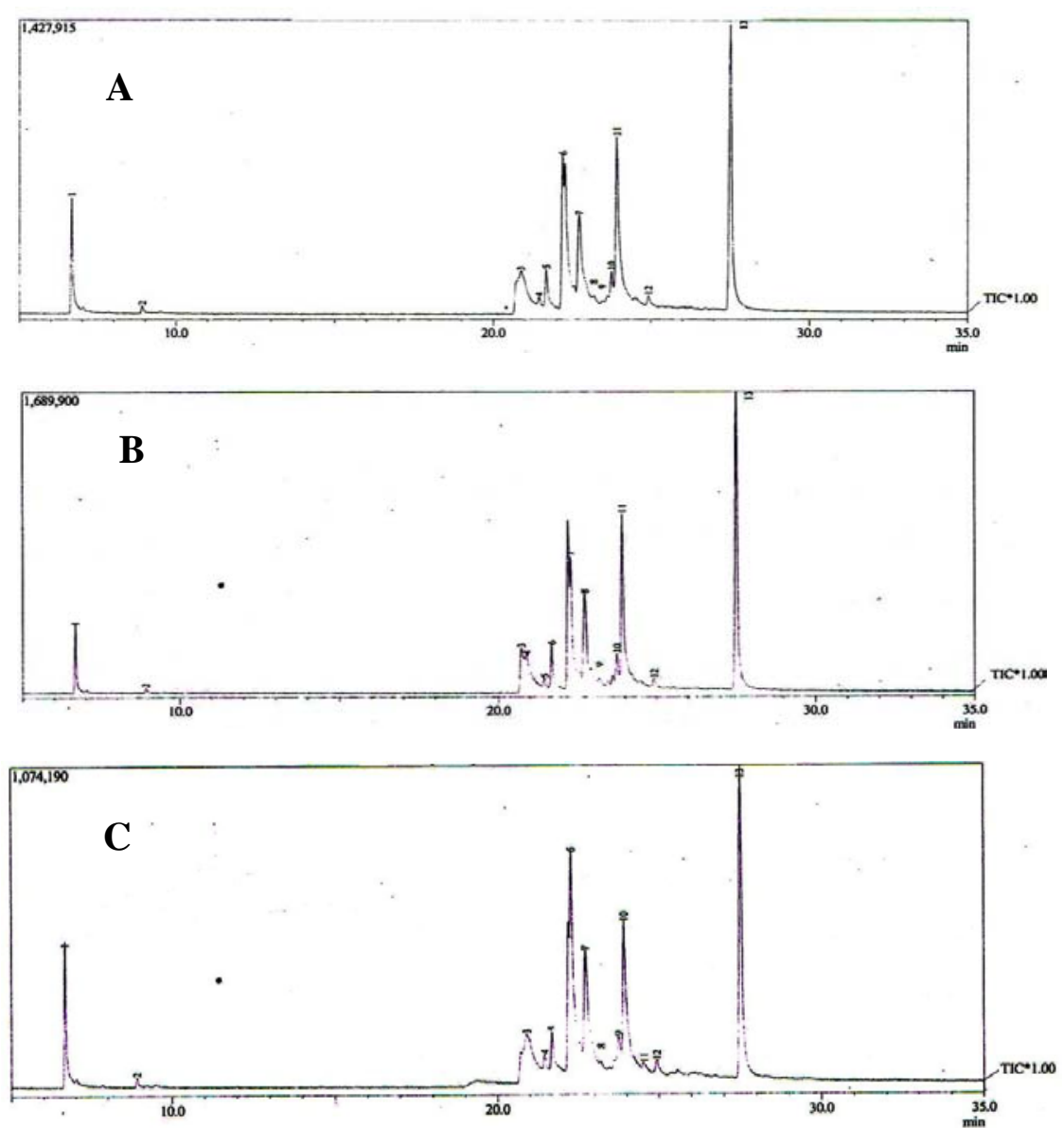


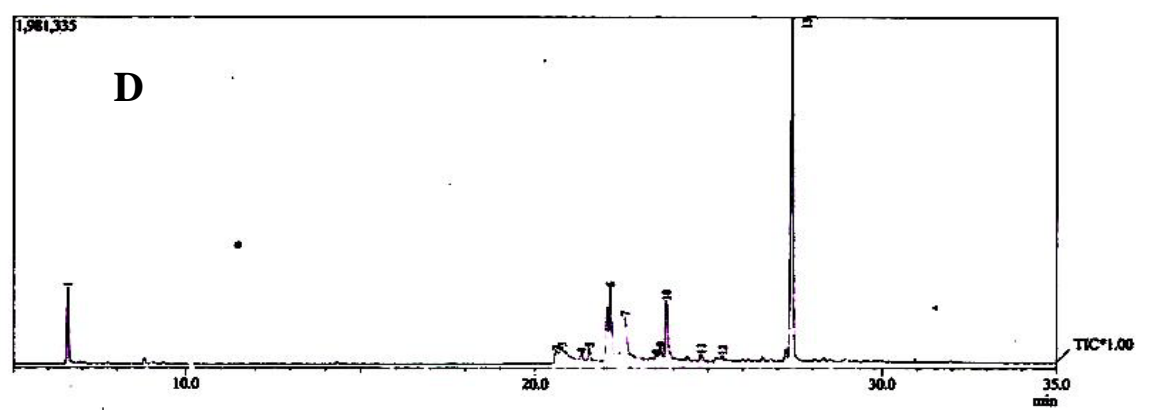

Gambar 16. Kromatogram minyak nilam A, B, C, dan D yaitu menggunakan air penyuling dengan $\mathrm{pH}$ 7, 9, 10 dan 12

- Grafik komponen utama penyusun minyak nilam menggunakan air penyuling pH 7, 9, 10 dan 12 disajikan pada Gambar 1.

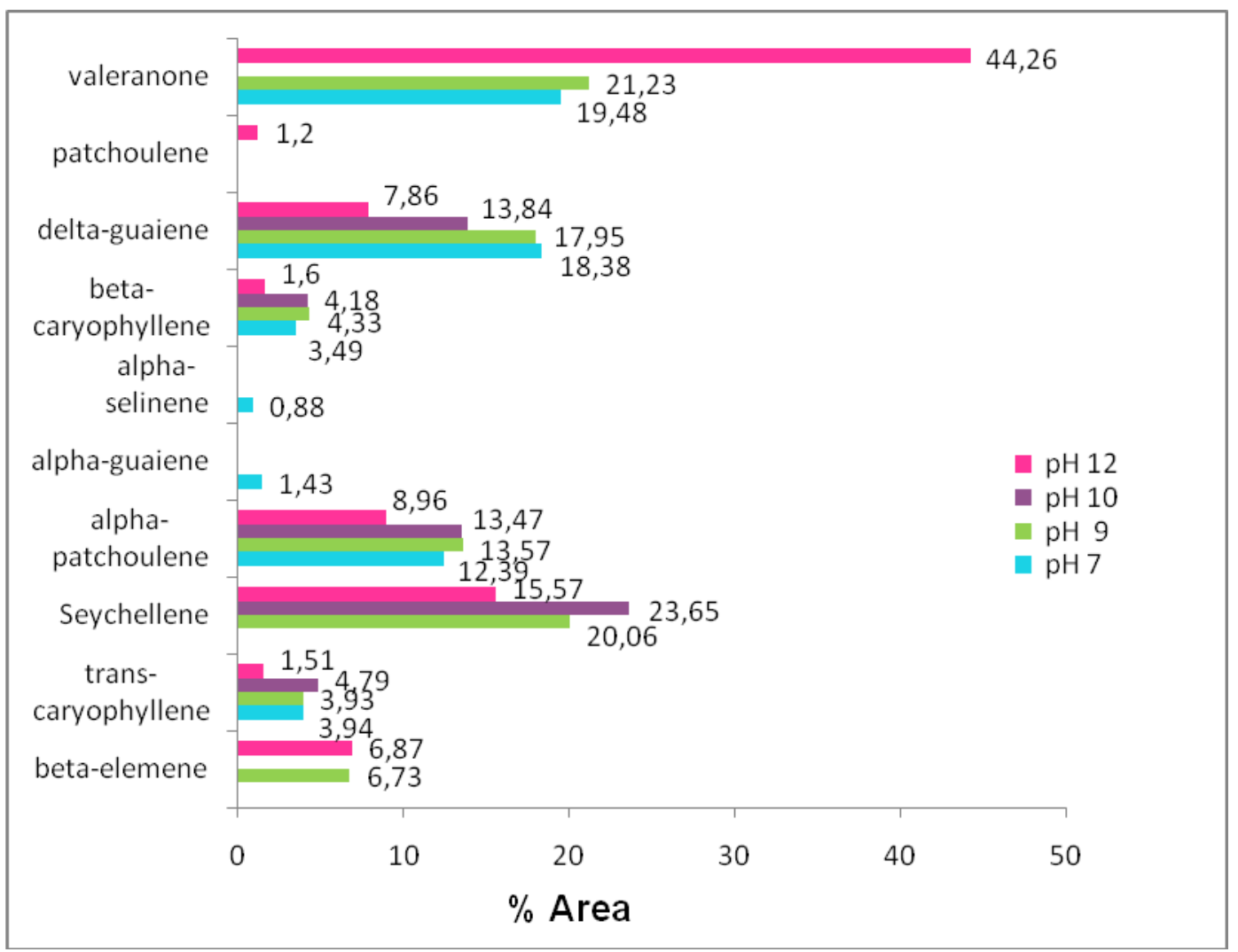

Pada Gambar 1 dapat dilihat bahwa tidak ditemukan adanya senyawa patchouli alkohol yang merupakan komponen utama penyusun minyak nilam dan komponen yang paling menentukan mutu minyak nilam. Kemungkinan pertama tidak ditemukannya senyawa patchouli alkohol adalah telah terjadi kerusakan pada komponen kimia minyak nilam. Kerusakan pada minyak atsiri dapat disebabkan karena terjadinya proses hidrolisa, oksidasi resinifikasi dan tercampurnya minyak dengan bahan lain serta pencemaran oleh wadah 
kemasan minyak. Mungkin juga penyimpanan minyak nilam yang tidak tepat dapat mempengaruhi kerusakan senyawa kimia pada minyak nilam.

Hal kedua yang menyebabkan patchouli alkohol hilang mungkin disebabkan kesalahan pada saat melakukan analisis dengan GC-MS, baik kesalahan yang terjadi karena human error maupun masalah pada alat GC-MS jenis Shimadzu QP 2010S yang tidak memenuhi standar yang sudah ditentukan atau alat mengalami kerusakan sehingga senyawa patchouli alkohol tidak teridentifikasi.

\section{KESIMPULAN DAN SARAN}

\section{Kesimpulan}

Dari penelitian yang telah dilakukan maka dapat diambil kesimpulan sebagai berikut :

1. Komposisi kimia yang terdapat di dalam minyak nilam yang telah disimpan selama tiga bulan secara keseluruhan tidak mengalami perubahan yang tidak signifikan.

2. Kualitas minyak nilam yang telah disimpan selama tiga bulan pada besarnya berat jenis, indeks bias, bilangan asam, bilangan ester dan kandungan logam besi ( $\mathrm{Fe}$ ) masih sesuai dengan Standar Nasional Indonesia (SNI-06-2385-2006).

3. Kadar patchouli alkohol dengan analisis menggunakan GC-MS pada sampel minyak nilam yang telah disimpan selama tiga bulan menggunakan air penyuling $\mathrm{pH}$ 7, 9, 10 dan 12 tidak teridentifikasi.

2. Saran

Berdasarkan penelitian yang telah dilakukan pada sampel minyak nilam yang telah disimpan selama tiga bulan menggunakan air penyuling $\mathrm{pH}$ 7, 9, 10 dan 12 masih perlu dilakukan penelitian lebih lanjut tentang faktor-faktor yang mempengaruhi kerusakan pada minyak nilam terutama tidak teridentifikasinya senyawa patchouli alkohol di dalam minyak nilam.

\section{DAFTAR PUSTAKA}

Day and Underwood. 1992. Kimia Analisis Kuantitatif. Edisi kelima. Penerbit Erlangga. Jakarta.

Harvey, D. 2000. Modern Analytical Chemistry. Mc Graw-Hill. New York.

Hayani, E. 2005. Teknik Analisis Mutu Minyak Nilam. Buletin Teknik Pertanian. Vol.10. Nomor 1.

Ketaren, S. 1986. Pengantar Teknologi Minyak Atsiri. Penerbit Balai Pustaka. Jakarta.

Mangun, S. 2008. Nilam. Cetakan ke III. Penebar Swadaya. Jakarta.

Rubiyanto, D. 2010. Diktat Proses Industri Kimia. Industri: Semen, Keramik, Kaca, Sabun-Deterjen, Cat Surface Coating dan Minyak Atsiri. Program 
Hibah Kompetisi Berbasis Institusi (PHK-I). FMIPA-Universitas Islam Indonesia. Yogyakarta.

Sastrohamidjojo, H. 2002. Kromatografi. Liberty. Yogyakarta.

Sastrohamidjojo, H. 2004. Kimia Minyak Atsiri. Universitas Gajah Mada Press. Yogyakarta.

Setiyowati, H. 2013. Peningkatan Kualitas Minyak Nilam dengan Modifikasi $p H$ Air Penyuling. FMIPA-Universitas Islam Indonesia. Yogyakarta.

Standar Nasional Indonesia (SNI). 2006. Minyak Nilam. Dewan Standarisasi Nasional. Jakarta. SNI 06-2385-2006.

Walker, T. G. 1969. The Structure and Synthesis of Patchouli Alcohol. Manufacturing Chemist and Aerosol news. 